\title{
ТЕОРЕТИКО-МЕТОДОЛОГИЧЕСКИЙ ПОДХОД К ИССЛЕДОВАНИЮ ПРИРОДЫ ИНСТИТУЦИОНАЛЬНЫХ ИЗМЕНЕНИЙ И ИХ ВЛИЯНИЯ НА ЭКОНОМИЧЕСКУЮ ДИНАМИКУ
}

\author{
(c) 2019 Михайлов Александр Михайлович \\ доктор экономических наук, профессор кафедры «Экономическая теория» \\ Самарский государственный экономический университет (СГЭУ), Россия, Самара \\ E-mail:2427994@mail.ru \\ (c) 2019 Петров Никита Анатольевич \\ кандидат экономических наук, доцент кафедры «Экономическая теория» \\ Самарский государственный экономический университет (СГЭУ), Россия, Самара \\ E-mail: petrovnikitamail@yandex.ru
}

\begin{abstract}
Современная экономическая конъюнктура все в меньшей степени поддается исследованию с использованием традиционных подходов к анализу динамики макроэкономических показателей. На взаимоотношения контрагентов рынка друг с другом, обуславливающие конкретную фазу экономического цикла, значительное воздействие оказывают институциональные факторы и изменения, вызывающие их нестабильность.
\end{abstract}

Ключевые слова: институциональные изменения, экономический цикл, фаза цикла, институциональные показатели, возмущения системы, финансовые шоки, институт, трансакционные издержки.

Институциональный подтекст в колебаниях современных экономических систем в последнее время прослеживается во все большей части работ ученых экономистов. Ныне устоявшиеся институциональные подходы к изучению экономической динамики обладают широкой институциональной базой. Теоретической основой в них являются права собственности, концепция трансакционных издержек, защита контрагентов от неисполнения условий сделок, а также конкуренция между участниками рынка, обладающими сравнительными преимуществами владения информацией и знаниями.

В наиболее распространенных теориях циклических колебаний можно заметить упоминание институциональных факторов экономического роста. Само определение “институт" можно описать в разных аспекта начиная от разработанных и требуемых к соблюдению “правил игры”, законодательно регулируемых государством, до категорий существующих экономико-психологических концепций, наподобие устоявшихся привычек, традиций и иного. В качестве примера можно указать на одного из отечественных авторов Л.П. Зенькову, которая исследовала продолжительность циклов и определяющие их Она считала, что анализ экономического цикла невозможно провести без детального исследования социально-психоло- гических и политических институтов [1]. Вышеуказанный автор изучал циклические процессы в ряде стран Латинской Америки и отмечал, что наиболее существенные изменения экономической конъюнктуры происходят именно в период институциональной перестройки. Им была выявлена взаимосвязь выхода экономики из кризиса при улучшении подходов к проведению государственной политики.

Продолжая исследование институциональных изменений, необходимо рассмотреть основные виды институтов. Мы можем выделить три ключевых института экономики: социально-психологические институты (или неформальные), социально-правовые (формальные) и существующие разнообразные государственные инструменты контроля и принуждения: в виде таможни, судов, Центрального Банка.

Современные теории экономических циклов, включающие институциональные факторы смены фаз цикла, в большей своей части опираются на концепцию социально-правовых институтов, основываясь на предположении о том, что с развитием данных институтов начинается процесс трансформации рынка. Институциональные циклы, основанные на трансформации социально-правовых институтов необходимо изучать как циклы, связанных с открытием новых ресурсов, техническими инновациями, проходящими 
в конкретных политических условиях.

Говоря о технических достижениях и институциональных факторах, способствующих их появлению, мы не можем обойти такого автора как К. Перес, разработавшей концепцию технико-экономической парадигмы, в которой ученый объединила циклические процессы с изменениями технологических, экономических и институциональных укладов [2]. Следует сказать, что в своих исследованиях цикличности экономической динамики, отечественные ученые В.Е. Дементьев, С. Ю. Глазьев, С.М. Меньшиков значительное внимание уделяли и следовали выдвинутым К.Перес теоретическим положениям.

Например, В.Е. Дементьев полагал, что для активации изменений в институциональной среде необходимо уйти от состояния институционального равновесия. Он описывал этот процесс как отказ контрагентов от условий первоначально заключенных договоров и не считавших для себя обязанными расходовать средства на реструктуризацию сделок [3]. Однако проводимая институциональная регламентация контрактных отношений понижает способность предпринимателей находить наиболее успешные организационные формы бизнеса в целях разработки и реализации инноваций и продуктов следующей длинной волны цикла.

Другой отечественный экономист, С.Ю. Глазьев, при исследовании циклических процессов, одним из основных факторов, их вызывающих, считает смену технологических укладов. Делая отсылки на работу К. Перес, Глазьев определил, что переход к новой фазе цикла со своим технологическим укладом завершается институциональными изменениями, способствующими формированию производственных и социально-экономических отношений, соответствующих новым требованиям технологический уклада [4].

С.М. Меньшиков, изучая причины длинных волн в экономике, указывал на фазу кризиса, как первый этап в длинном цикле. Причем основой для кризиса он считал противоречия между технико-экономической подсистемой и институциональной средой [5].

Отельные исследователи экономических циклов, происходящих в разное время в России, в частности О.Э. Бессонова, считают, что каждый последующий тип экономической развития становился на своей собственной институцио- нальной среде, со своими, присущими только данному этапу развития экономики, институциональными формами [6]. Одним из основных факторов трансформаций в российской экономической среде, Бессонова видит компенсационное взаимное воздействие друг на друга институтов рыночной торговли и частного предпринимательства. Данная институциональная форма способна создать, так называемый, квазирыночный механизм, которому, при первом приближении присущи ключевые категории рынка в виде института частной собственности, ценообразования в результате конкуренции, контрактные отношения с равенством обязующихся в сделке сторон). На сегодняшний день российский рынок не соответствует типичным рыночным отношениям. В нынешних реалиях российской экономики, фирмы не стремятся разработать стратегию развития, ориентированную на рынок. Им значительнее выгоднее вести борьбу за государственные ресурсы в самых разных их проявлениях, основываясь на своих связях в правительстве в целях установления контроля над конкуренцией и переходу на рынок несовершенной конкуренции.

Иные отечественные экономисты также указывают на роль частного предпринимательства в прохождении институционального развития. Однако их влияние не ограничивается спектром, характером и частотой совершаемых операций на рынке. Сами структурные изменения в предпринимательстве способны изменить институциональную среду. Так. Г.Б. Клейнер полагает, что в отдельных предприятиях создаются микроинституты, основанные на комплексах ролевых отношений в данной организации, которые определяют реакцию предприятия на воздействие внешних шоков [7].

Происходящие трансформации экономических институтов связаны с существованием и неравномерным распределением экономической ренты, стратегией национального правительства провести инновационные мероприятия с национальной экономикой через индустриализацию основных отраслей, а также сложившимися изначально условиями экономического развития.

Существуют отдельные подходы, сделавшие упор в исследовании институциональных преобразований на правовые институты, а также институт собственности [8].

Мы полагаем, что одной из причин нерав- 
номерности экономического развития выступают институциональные аспекты в отношениях собственности на производственные факторы. Институт собственности способен отразить действующую экономическую инфраструктуру, учитывая все возможные варианты объединения личных и вещественных факторов производства. Можно говорить об определении структуры производственного процесса, подходов к распределению произведенных благ, осуществляемого обмена и уровня потребления общественного продукта самим институтом собственности. Институциональная категория собственности является конкретным результатом уровня социально-экономического развития в конкретном временном интервале. Изменения в структуре собственности являются разновидностью структурных сдвигов в экономике.

Одно из ведущих исследований воздействия трансформации институциональных интересов собственников производственных факторов на переход к постиндустриальной экономике принадлежит перу российского ученого А.М.Михайлова. Помимо прочего, он изучал проблему выхода экономики с неэффективными институтами из «ренториентированной ловушки» [9]. Михайлов полагает, что если продолжать поддерживать неэффективные для экономики институты, то неизбежны сокращения доходов и рост трансакционных затрат.

На наш взгляд, сами по себе, институциональные изменения призваны уменьшать издержки трансакций. Чрезмерные издержки в одном из видов трансакций и потеря контроля их роста может являться причиной циклических колебаний в экономике. Поэтому в вопросе стабильности институциональной среды и нивелирования отрицательных последствий институциональных преобразований главным становится вопрос снижения трансакционных издержек. На это обращает внимание Л.В. Левченко, указывая, что помимо существующих корпоративного, государственного и академического институтов необходимо развивать и отдельные механизмы коммуникаций между контрагентами [10].

Мы полагаем, что циклическое развитие является поэтапным, каждый следующий цикл отличается от предыдущего уровнем технологических прорывов, последствием финансовых “шоков”, политическими факторами. В данном случае мы также считаем, что на поэтапность развития экономики влияет величина накопленного институционального капитала, который в реальных экономических условиях способен дестабилизировать экономическое развитие. Все вышеперечисленное можно охарактеризовать как «возмущениями системы» (показатель Е) резкими изменениями институциональной среды.

Мы считаем, что очередные трансформации в экономической среде проходят в более развитой относительно своего предшествующего состояния экономической системе, следовательно график циклического развития примет “ступенчатый” вид (рисунок 1.1). Введем еще ряд по-

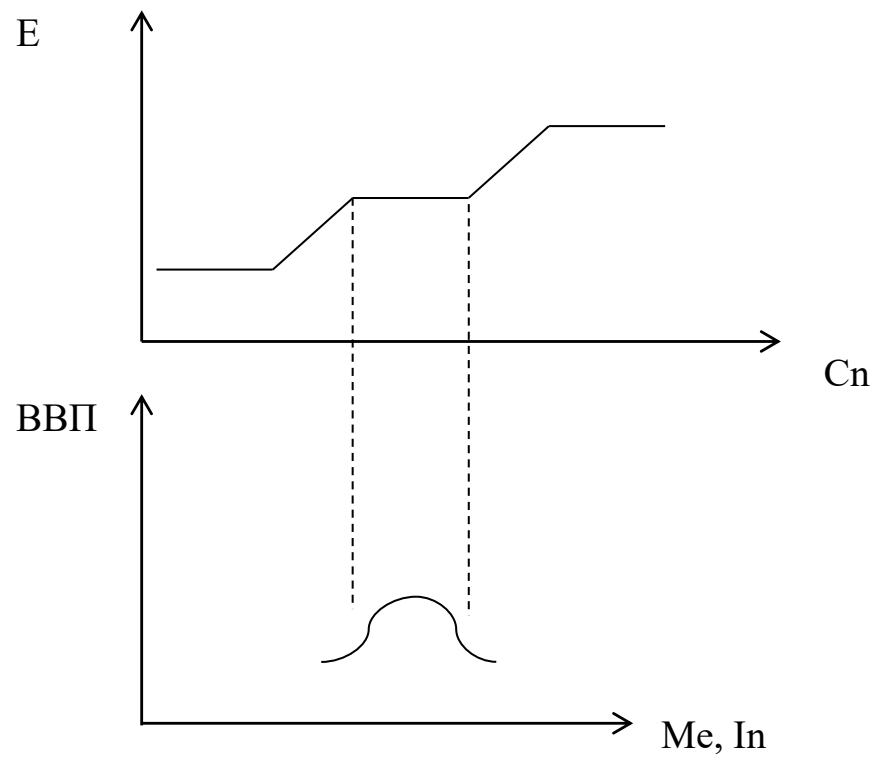

Рисунок 1.1. Циклические процессы в экономике 
казателей, в дальнейшем используемых нами для исследования степени влияния институциональных изменений на экономическую динамику: $\mathrm{Cn}$ - динамика ВВП, Ме - макроэкономические показатели, включающие совокупный спрос, предложение, объем инвестиций и сбережения, а также уровень занятости; In - можно охарактеризовать как совокупность показателей институциональной среды (включая агрегированный индекс Polity, человеческого капитала, уровня развития бизнеса, накопление трансакционных издержек, свободу выбора вида деятельности).

В ситуации, когда Е можно принять за константу, на динамику ВВП влияют институцио- нальные и макроэкономические факторы. ВВП может изменяться в трех вариантах (рисунок 1.2 б). Во-первых, при неизменных Мe, In - что возможно в краткосрочном периоде: политические, технологические изменения. Во-втором случае трансформируются Me, In, а ВВП меняется несущественно в результате поддержания его на прежнем уровне с помощью золотовалютных резервов. Третий вариант - совокупное изменение показателей.

Также волне возможна ситуация отрицательных возмущений системы (рисунок 1.3, продолжение циклических процессов в сценарии II, III). Такие изменения могут проявляться в виде случайных изменений, а также в виде заранее

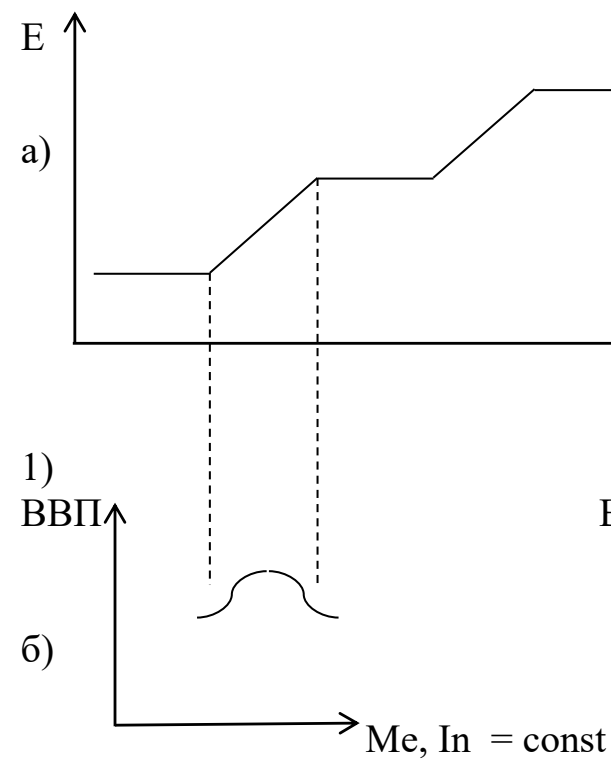
$\rightarrow \mathrm{Cn}$

2)

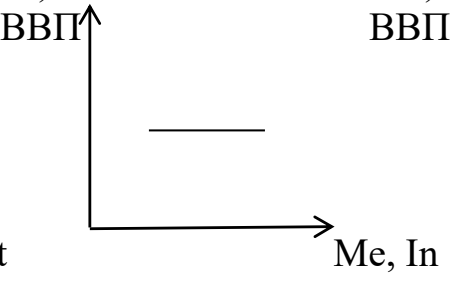

3)

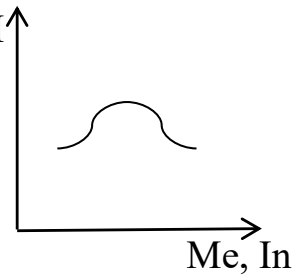

Рисунок 1.2. Динамика макроэкономических показателей:

а) "ступенчатое" развитие экономики;

б) ситуации развития экономической системы

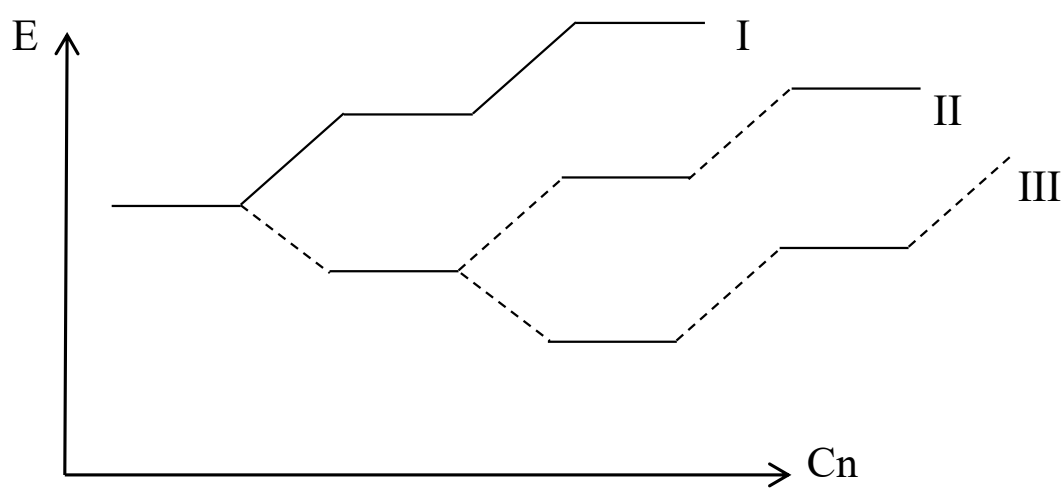

Рисунок 1.3. Сценарии вероятного развития экономической системы 
спрогнозированных, но по ошибке получивших незначительную долю вероятности наступления, например - финансовые “шоки”. Тогда поэтапный график динамики циклических процессов будет отражать вероятности, по которым будет развиваться экономическая система.

Мы считаем, что важным выводом из произведенного анализа является получение представления об отсутствии обратной динамики цикла. Даже учитывая отрицательные возмущения системы, циклическое экономическое развитие предполагает переход экономики на новый этап и отсутствие регресса в долгосрочной перспективе.

Важным аспектом циклического развития являются процессы инноваций, причем не только в производстве, но и в институциональной среде. Одной из важных предпосылок становления и развития процесса инновационной модернизации являются зрелость и устойчивость институциональной среды [11]. На наш взгляд в тих целях необходимо использовать сформированные сегодня институты развития: Банк развития, Российская венчурная компания, Инвестиционный фонд России, особые экономические зоны, технопарки.

Считаем важным указать, что инновационному развитию в России могут помешать существующие институциональные ловушки. Напри- мер, М.Ю. Малкина выделяет следующие виды подобного рода ловушек: психологическая неготовность участников рынка; ловушки рентоориентированного поведения, проявляющиеся в борьбе за доступ к сфере извлечения ренты [12].

Мы считаем, что в нынешнее время существуют также ловушки в виде нежелания бизнеса инвестировать средства в свое развитие, вследствие дороговизны подготовки исследовательской базы. Основными источниками дохода бизнес видит в сохранении связей с основными контрагентами и формированию схем ухода от налогообложения. Одним из направления преодоления подобного институционального ограничения является создание особые институциональных режимов, способствующих развитию налогового стимулирования посредством введения субсидий.

В области планирования создания институтов, управляемого замещения одних институтов другими и выбора преобладающего режима институциональной динамики в экономической науке на сегодняшний день сделано мало. Преобладающее на сегодня число макроэкономических моделей учитывает минимальное влияние институтов на экономическую динамику. Поэтому становится важным определение схемы ввода новых институтов, особенно в период депрессии, как фактора будущего роста.

\section{Библиографический список}

1. Зенькова Л.П. Институциональные подходы к циклам зарубежных экономистов // Экономика и управление. - 2009. - № 2.- С. 12 .

2. Перес К. Технологические революции и финансовый капитал.-М.: Дело, 2011.- С. 232.

3. Дементьев В.Е. Длинные волны экономического развития и финансовые пузыри.- М.: ЦЭМИ РАН, 2009.C. 21.

4. Глазьев С. Ю. Современная теория длинных волн в развитии экономики.- М.: Дело. - 2005.- С. 18-19.

5. Меньшиков С. М., Клименко Л.А. Длинные волны в экономике. Когда общество меняет кожу.- М.: Международные отношения, 1989.- С. 234-235.

6. Бессонова О.Э. Институциональная модель российской экономики: ретроспектива и современный вектор развития// ЭНСР. - 2008. - № 4 (43).-С. 29.

7. Клейнер Г.Б. Институциональные факторы долговременного экономического роста // Экон. наука современной России. - 2000.- № 1.- С. 15.

8. Курманова Л. Р., Курманова Д.А. Синергия институциональных и экономических изменений в деятельности коммерческих банков // Вопр. экономики и права. - 2011. - № 12.- С. 25.

9. Михайлов А.М. Реализация экономических и институциональных интересов в процессе становления в России постиндустриального общества // Вестн. Самар. фин.-экон. ин-та. - 2011. - № 2.- С. 4.

10. Левченко Л.В. Развитие институциональной системы взаимодействия факторов производства под влиянием НТП // Вопр. экономики и права. - 2012. - № 7.- С. 22.

11. Гасанов М. А., Тютюшев А.П. Воздействие институциональной среды на структурные сдвиги экономики // Вестн. наук Сибири. - 2012.- № 1 (2).- С. 169.

12. Малкина М.Ю. Институциональные ловушки инновационного развития российской экономики // Журн. институциональных исследований.- Т. 3.- 2011. - № 1.- С. 53-59. 